\title{
A Brief Introduction to Transrational Peace Research and Elicitive Conflict Transformation
}

\author{
Wolfgang Dietrich
}

Submitted: September 2013

Accepted: March 2014

Published: November 2014

\section{Abstract}

This article is a summary of the author's Many Peaces trilogy, which comprises, in its original version, more than 1,200 pages. Volumes one and two were published by Palgrave Macmillan in London 2012 and 2013, with the third volume still to be issued.

It presents a broad range of peace interpretations in history and culture, which are divided into the so called five peace families - the energetic, moral, modern, post-modern and the transrational perceptions and understandings of peace(s).

It further elaborates the transrational peace philosophy, and derives from John Paul Lederach's famous pyramid of conflict (work) a broader systemic understanding of conflict as a relational phenomenon. It offers a tool for analysis of the complex processes that happen at human "contact boundaries at work" - the enlarged pyramid-model of themes, levels and layers.

Finally, it introduces resonance, correspondence and homeostasis as principles of elicitive conflict mapping, the methodological toolkit for applied conflict work.

\section{Keywords}

peace philosophy, conflict transformation, conflict mapping

\section{WHAT IS TRANSRATIONAL PEACE PHILOSOPHY?}

Transrational peace research is a relatively new term that we coined at the University of Innsbruck's UNESCO Chair for Peace Studies at the beginning of this millennium. It results from our research on different perceptions and interpretations of peace in history and culture. Principally, we found four major groups of interpretation, which we called the energetic, the moral, the modern and the postmodern peace families. Each circulates around a specific key value: energetic peace is all about harmony, the moral interpretation emphasizes justice, the modern understanding of peace calls for security, and the postmodern approach deals with the question of truth(s). Since none of these values appear isolated in social life, we tried to combine them in a holistic manner and identified the dynamic equilibrium of the four aspects as a larger concept of peace. We called this trans-rational, because it appreciates and applies the rationality of modern science while it transgresses its limits and holistically embraces all aspects of human nature for its interpretation of peace. It is rational and so much more, for example emotional, mental and spiritual (Dietrich, 2008 p.319-405). Transrational peace research as an academic endeavor is concerned with the encounter, the relations, the communication styles and the behaviors of human beings, 
Journal of

http://journal-of-conflictology.uoc.edu

understood as "contact boundaries at work" in the tradition of Gestalt therapy (Quitmann, 1996 p. 109-111). If and when these encounters at contact boundaries at work are disturbed, then the episodes are referred to as conflicts in common language. We are looking for proper methods for dealing with such conflicts in the logical framework of transrational epistemology.

The term transrational is borrowed from Ken Wilber (1995), whose philosophy is one of many inspirations but not a guideline for us. The Innsbruck school is not a branch of Wilber's integrative approach. We do not share his evolutionist epistemology. Nonetheless we took Wilber's well-known matrix of internal and external, respectively individual and collective aspects of human orientation, as a blueprint for our model of the interrelatedness of the peace families and their combination to the dynamic equilibrium that we call Transrational Peaces:

Figure 1. The matrix of transrational peaces

(First published in Dietrich, 2008, p. 385)

\begin{tabular}{l|ll}
$\begin{array}{l}\text { Interior } \\
\text { Energetic and postmodern }\end{array}$ & \multicolumn{2}{l}{$\begin{array}{l}\text { Exterior } \\
\text { Moral and modern }\end{array}$} \\
\hline $\begin{array}{l}\text { Intentional } \\
\text { Peace out of harmony }\end{array}$ & $\begin{array}{l}\text { Behavioral } \\
\text { Peace out of security }\end{array}$ & $\begin{array}{l}\text { Singular } \\
\text { (individual) }\end{array}$ \\
\hline $\begin{array}{l}\text { Cultural } \\
\text { Peace out of truth }\end{array}$ & $\begin{array}{l}\text { Social } \\
\text { Peace out of justice }\end{array}$ & $\begin{array}{l}\text { Plural } \\
\text { (collective) }\end{array}$ \\
\hline
\end{tabular}

While the matrix is an attempt to present the research work of more than a decade in a nutshell, the academic endeavor will only be of relevance if it can be applied in practical peace and conflict work. For this purpose we related our findings to the praxis-oriented work of John Paul Lederach (1997, p. 30), who at the beginning of his career derived a pattern similar to ours from the Bible's Psalm 85:10: "Love and faithfulness meet together; righteousness and peace kiss each other." From the psalm, he drafted his matrix of the four basic values of truth, mercy, justice, and peace. He denominated his matrix "A Place of Reconciliation" (Lederach, 1997 p.28).

Of even more importance for peace research was Lederach's often copied and variegated pyramid of conflict. In its original version, this pyramid (Lederach 1997 p.39) indicates that all actors in a dysfunctional or conflicting system interact across the various social strata, from the grassroots to the middle range of regional experts, and leaders to heads of state. And that they all are relevant to the process of transformation following the experience of violence. Therefore, according to Lederach, the actors have to be addressed in a contextual manner, using appropriate forms of intervention. His main merit, thus, was shifting the attention from the individual or the group to the relation as the key factor of conflict work. By doing so, his model became a groundbreaking initiator of the transition from mechanistic to systemic thinking in peace and conflict studies, which was crucial for the development of transrational peace research. The original version of Lederach's pyramid looked as follows:

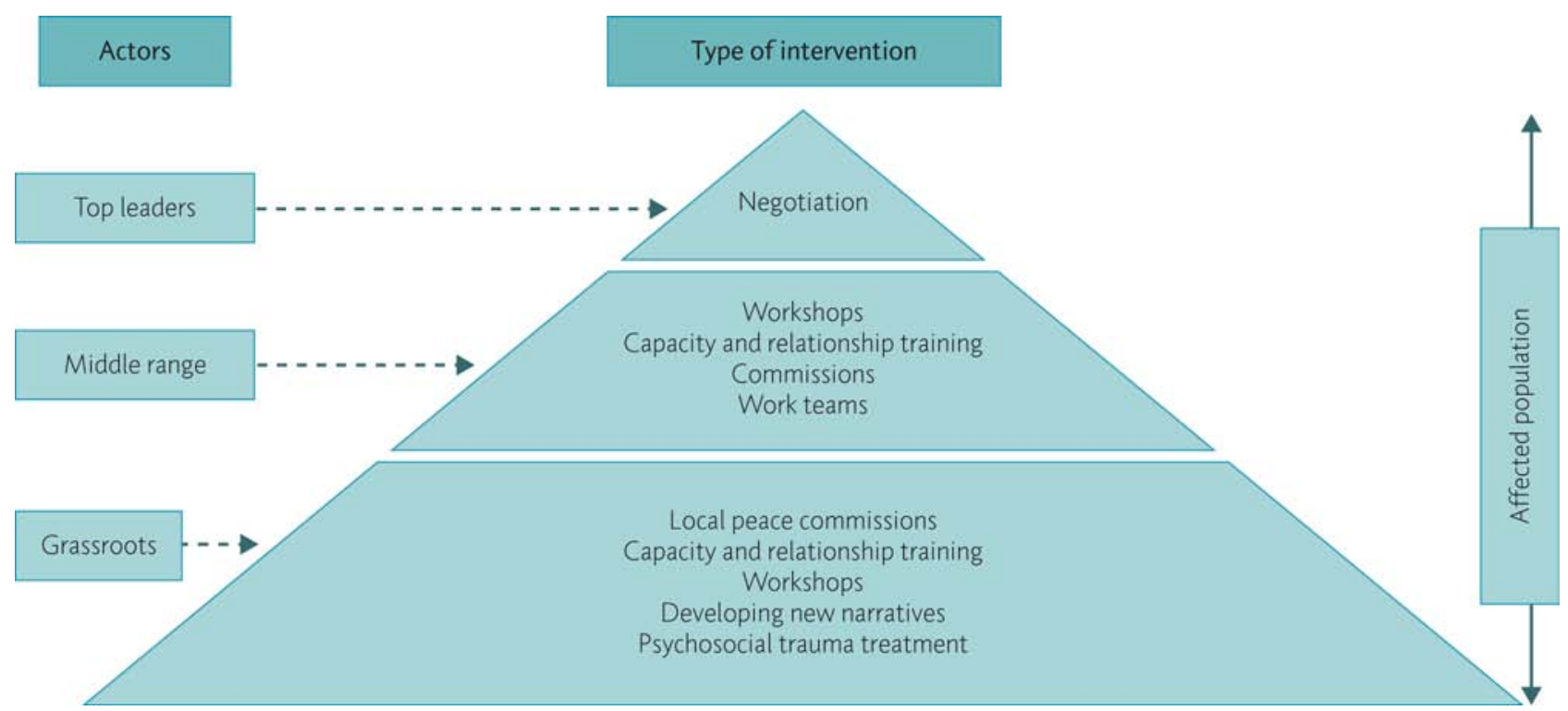


Lederach's pyramid was initially provided in this strictly vertical lateral view. He only implicitly included the four biblical values in his diagram, which therefore was two-dimensional. But Lederach (1997, p. 82 and 2003, p. 27) expanded Johan Galtung's (1990, pp. 291-305) wellknown triangle of physical, structural, and cultural violence to a fourth dimension. He divided Galtung's physical into a personal and a relational aspect. He thus acknowledged the connection between a person's internal processes and social relations, which in turn consist of immediate situations, a wider context, and a deeper layer of perception, interpretation, and action. The inevitable and constantly renewed need for responsible choices, taken by people born free, thus became the systemic foundation of his conflict work. This inspired us to expand the pyramid by rendering it to represent four quadrants: 'person,' 'structure,' 'relation, and 'culture,' rather than as a two-dimensional structure. Viewed from the top, the pyramid looks like this:

Figure 3: Lederach's pyramid enlarged to the three-dimensional transrational model; bird's-eye view

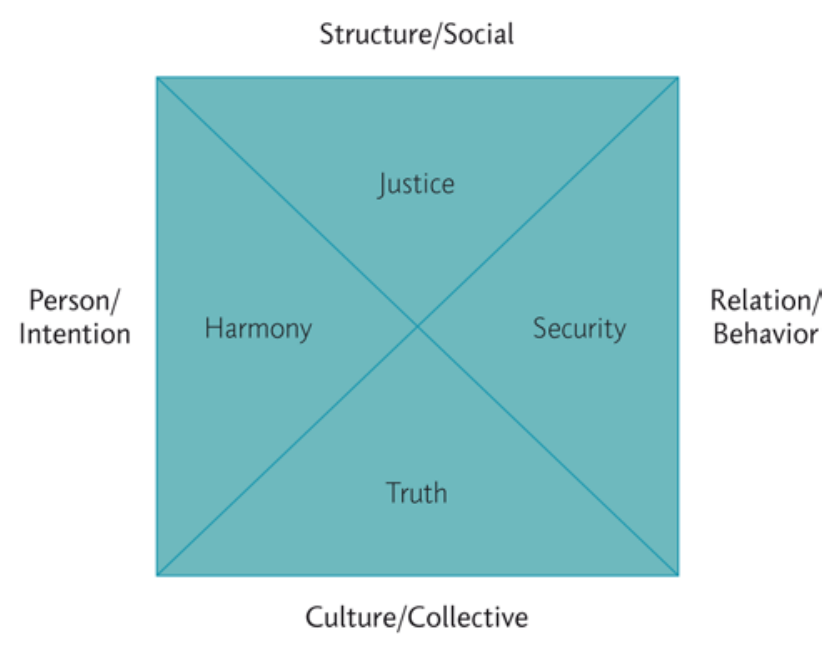

This allows for the consideration of human existence as a contact boundary at work benefiting from the accomplishments of humanistic psychology, while initiating the spiral from the episode to the epicenter of a conflict, as Lederach (2003, p. 10-11) said. The episode is what we perceive as the immediate and visible situation on the surface of a conflict. The epicenter, which is the driving force of life, can only be found beyond the deeper layers of the involved people's Ego. One needs a well-trained eye and a lot of empathy to see beyond the presented problems towards the deeper patterns of relationship, including the context in which the conflict finds expression. It followed that intrapersonal issues of sexual desire, social belonging, emotional attachment, and mental consciousness became themes in peace research and conflict work, as did the interpersonal spheres of family, community, society and global policity. The correspondence of the interior and exterior dimensions is further considered for each aspect. The transrational meaning of the pyramid, that is, of conflict, cannot be comprehended on the basis of an episode on its surface. The person, as introduced by Lederach, corresponds to the individual and the interior, which is the energetic quadrant of peace out of harmony in transrationality.

Individuals mostly perceive peace as the harmonious flow of all existing things, as long as they are not asked about religious, cultural, societal or political values and norms. In the diagram this quadrant of peace through harmony is therefore referred to as the gateway to the layers behind the persona. We see, thus, the correspondence between a person's internal processes and social relations - relations, which in turn consist of immediate situations, a wider context, and a deeper layer of perception, interpretation, and action. The desire for peace through harmony leads from the outermost layer to the next deeper layer. The inner layers, as promoters or disturbers of harmony, affect the outer ones and vice versa. The pyramid must therefore be thought of as a matryoshka doll, or a Chinese box, on the inside of which there are the smaller pyramids of the Ego and the Self as a multi-layered epicenter. Franz Ruppert (2002, p. 49) suggests the following therapeutic layers between the social episode and the energetic epicenter: society, kinship, core family, subject, body, organs, cells, and atoms. In its most radical variant, this thinking comprises all conceivable layers, from the atomic to the cosmic. However, in terms of peace and conflict research as a social science, it is enough of a challenge to consider the layers that unmistakably seep through the mask of the personae and that unmistakably contribute to the conflict episode on the surface.

In order to name the layers below the material and personal surface, I refer to the chakra philosophy of Tantra Yoga in the tradition of Patanjali and Shankara (Bharati, 2001, pp. 59-431). Accordingly, there is a sexual, a socioemotional and a mental layer underneath the material and personal surface, the episode of the Ego's contact boundary at work. Beyond (inside) the mental layer there is the spiritual layer, which does not refer to the Ego anymore but to what Yoga-Philosophy calls the Self, the aspect of every person that remains after dismantling all Ego layers. Because it is natural human property and potential, the spiritual layer is principally accessible for every person but it is hard to say anything meaningful about it, precisely because it is trans-rational, beyond reason. The mind does not have words for it, though peak- and peace-experiences happen precisely there, when the Ego is twisted, that is, when for a moment the primordial, harmonious and eternal unity of individual and universal existence is experienced by the human being. Therefore peace research has to take into account the high relevance of this human aspect for every theme, relation or action, but it cannot be addressed or 
defined only in a rational manner. It demands trans-rational methods and understanding. This opens up a most intriguing chapter for peace research. I try to articulate this model of layers by adding a lateral cross-section to Leder- ach's pyramid. In doing so, I do not identify empirical categories but rather suggest a visual pattern of analysis and description:

Figure 4: The intrapersonal layers of Lederach's pyramid, lateral view (first published in Dietrich, 2011, p. 355)

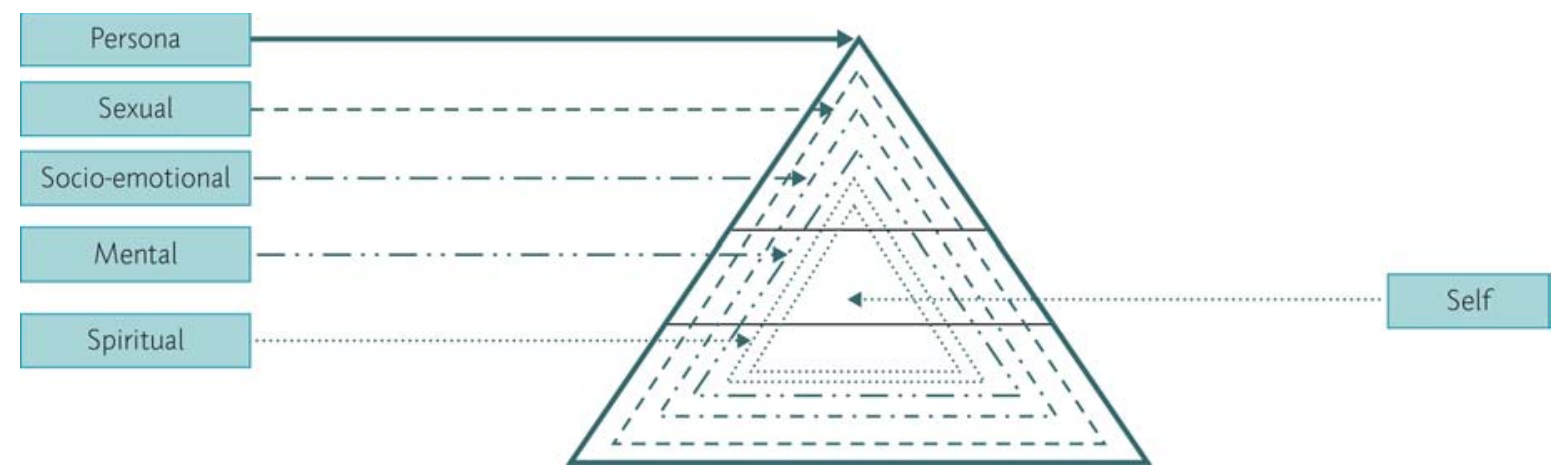

In keeping with the matryoshka doll principle, the inner layers of the pyramid possess the horizontal fields and vertical dimensions of the material-personal surface. The matryoshka layers are connected and interact with each other, and must not be thought of as merely stacked on top of each other while remaining separate. Overlaying my own matrix of transrational peace with Lederach's concept results in the images below, in which the inextricable connection between the interior and the exterior, and the individual and the collective processes along the human contact boundary at work, becomes apparent. This rendering of the pyramid brings together the notion of transrational peaces with Lederach's practical approach. In a first step, I offer a top view of the layers contained in the above cross section:

Figure 5: The intrapersonal layers of Lederach's pyramid, bird's-eye view (first published in Dietrich, 2011, p. 356)

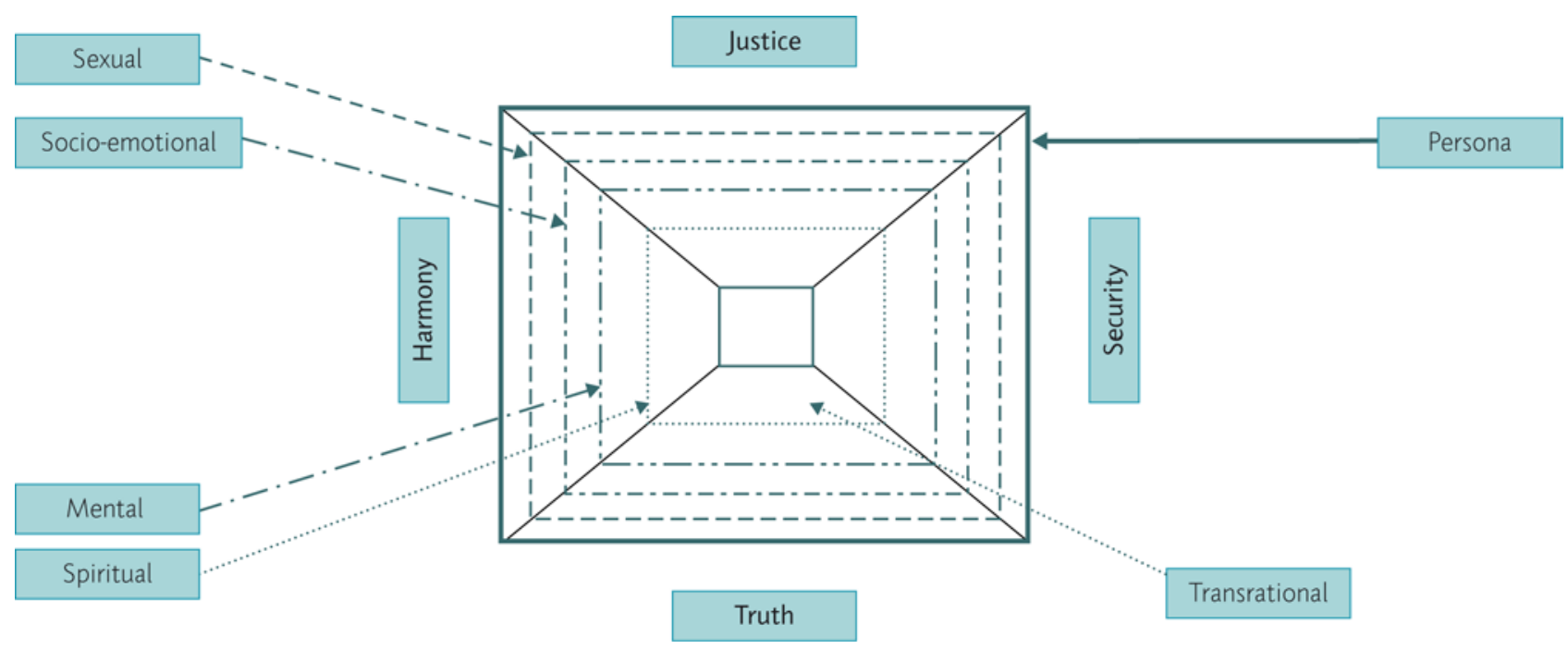

Virtually all schools of humanistic psychology describe intrapersonal stratifications that are remarkably similar to social stratifications. This is also the basic assumption of the Tantric principle of correspondence. I follow them. The layers located outside the material and personal surface of the persona can be called family, community, society, policity and global layers. Except policity, all these are terms widely applied in systemic and transpersonal psychology (Ruppert, 2002, p. 49) and understood in everyday speech. Policity is an artificial word, which we coined for the primordial human awareness of our existence in physical time and space, the precondition for the mental understanding of ourselves as social beings and any idea about social organization. 
All of these layers silently influence interpersonal conflict as they appear on the visual surface of the personae. That is, if I have a personal conflict with somebody else, my family, kinship, society and policity play an invisible and silent, yet significant role in the background. The same is true for the intrapersonal layers. The sexual, emotional, mental and spiritual aspects of my personality influence the behavior on the surface and my performance in a conflict. No episode is ever a strictly inter-personal or inter-so- cietal conflict, but always a transpersonal or trans-societal one - the disruption of the relational balance within a single system. As the second step I therefore now add to the above diagram those layers that are outside the surface, or mask, of a persona. In this pragmatic approach I regard the Tantric principle of correspondence: as within, so without. By doing so I arrive at the final and complete diagram of Transrational Peace:

Figure 6: The inter- and intrapersonal layers of Lederach's pyramid. The diagram of Transrational Peace, bird's-eye view (First published in Dietrich, 2011, p. 357)

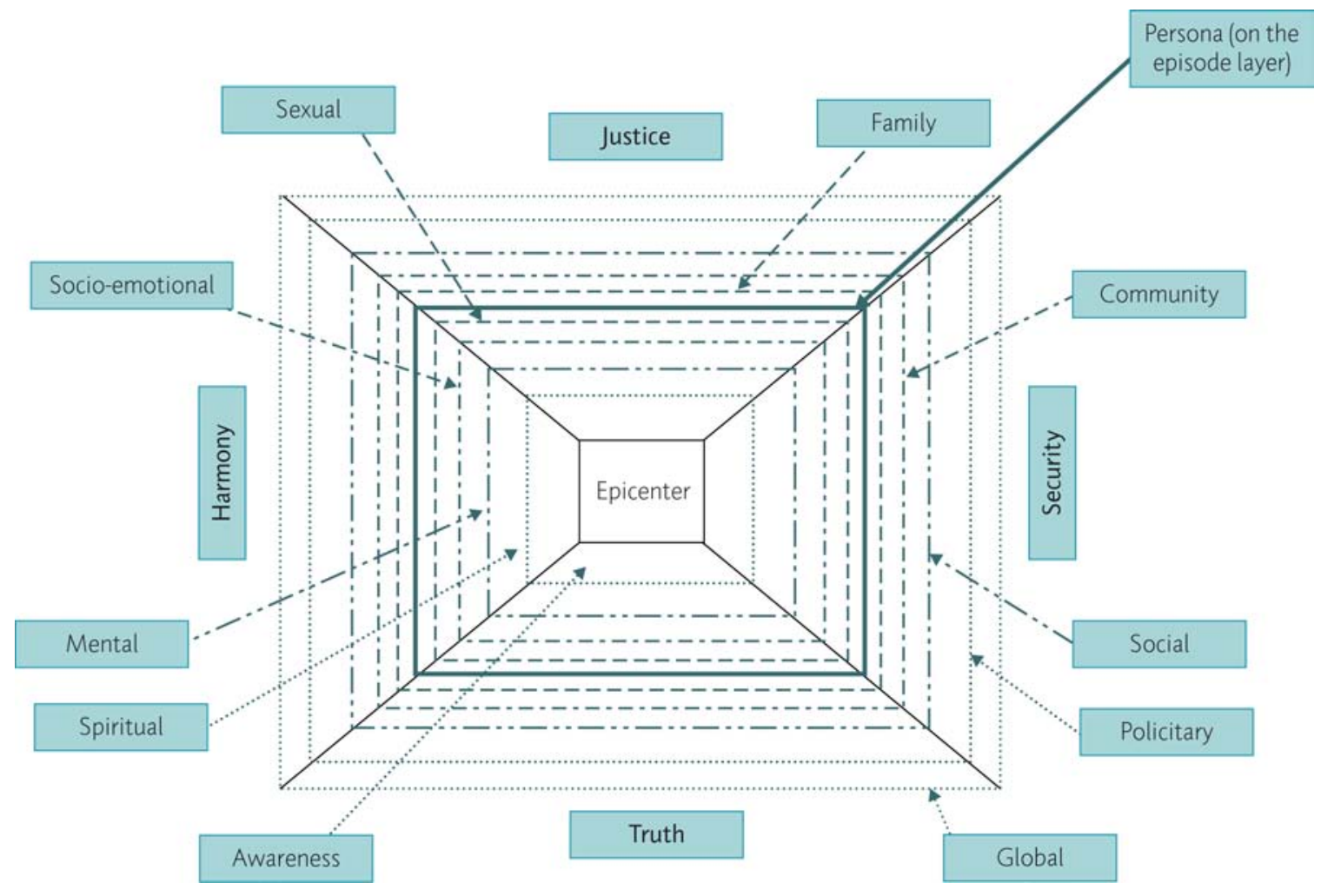

Crucial for proper understanding of this diagram is the principle of systemic homeostasis, which appears here simply as an aspect of balance. Figure 6 has to be seen as a metaphorical floor plan of Lederach's pyramid, imagined floating on the streams of life. If one side is overburdened, the building will collapse. Likewise, if a single aspect is overemphasized in conflict work, for example security, then harmony will be undermined and truth and justice destabilized. Applicable to all combinations, the system collapses once a bifurcation is reached. By the same token, a building will collapse, a ship will capsize, when the upper floors rest too heavily on the foundations, while working only on the foundations means there will never be a roof. Applied to conflict work, this metaphor emphasizes that all individual and social interrelations in the conflict system must be considered, and all levels of the pyramid. After all, even the most delicate ornamentation will not survive if the walls behind it are not stable and do not rest on a solid foundation. Thus, all the layers categorized earlier are of relevance. While working on one, we should not lose sight of the others, for an imbalance among the layers can just as easily bring down the entire system. To cite an extreme example, someone working exclusively on the spiritual layer may overlook the social and intellectual layers.

Some may object and suggest that this pyramid model, with its vertical levels, horizontal themes, intrapersonal and transpersonal layers, all of which are connected by a desire for harmony, is too complex to be applied in practice. Such objections may even be justified with particular respect to my emphasis that, when considered in a situational and 
relational context, these are not clearly distinct categories, but only typical and overlapping tools for meaningful understanding. However, given that social systems are inevitably dynamic and - whether we like it or not - complex, this rationality has an extremely limited reach. As a result, conflict work that focuses on the epicenter of the entire context rather than on the surface of an episode, must not limit itself to reductionist rationality. The complexity of social interrelations can be described only in transrational terms. As a consequence, transrational peace research cannot limit itself in its applied methodologies to just rational conflict engineering. It needs methods that address all aspects of human nature because they all define conflicts and the way we deal with them. Conflict workers need a toolkit that allows them to apply rationality and also methods that work on the sexual, emotional, mental and spiritual layers, which correspond to the familial, communal, societal and policity layers. These methods have to be effective in the sub-conscious, the conscious and the super-conscious layers. We found this ideal toolkit in John Paul Lederach's approach to Elicitive Conflict Transformation, which works principally with present realities and their complex systemic interrelations. The most important resource for sustainable peace work is the relational web of the people concerned.

\section{WHAT IS ELICITIVE CONFLICT TRANSFORMATION?}

The adjective elicitive does not appear in any standard dictionaries of the English language. Lederach (1995, p. 3773) derived it from the verb to elicit, meaning to bring forth or to evoke. The term was initially used in Gestalt therapy and humanistic psychology as synonymous with evocative; it refers to processes in which therapists provide the framework but not a guideline for their clients' transformation (O'Connor and Seymour 1992, p. 92). This says much about its use in peace studies and applied conflict work. Elicitive suggests in this context that the relational energy of the conflicting parties provides the method and the direction of transformation. Elicitive conflict transformation thus draws out, highlights, and catalyzes existing or communally held knowledge related to transforming conflicts between individuals, groups, and communities, while prescriptive approaches prefer prefabricated models. Lederach's definition did not simply propose a new label for old techniques and objectives. The term refers substantially to the transrational shift in the understanding of peace and conflict (Dietrich, 2008 and 2011, pp. 347-383). More precisely, elicitive conflict transformation is the methodological consequence of transrational peace philosophy.
From the methodological approach derives an understanding of conflict, conflict work and the required personal profile of a conflict worker that differs significantly from the conventional views of conflict resolution or prescriptive conflict transformation that can often be found, for example, in UN mission handbooks. It does not provide to-do-manuals, remedies or prefabricated solutions; it trusts the transformative energy that arises from the conflicting parties and their relations. And according to the principle of resonance, it expects the conflict worker to perceive this energy and provide a proper framework for transformation without taking the lead or imposing his or her own concepts on the conflicting parties.

Elicitive conflict transformation is a method, an art and a science. I will list some practical tools. But before I do so, I want to talk about the training of elicitive conflict workers, because this method requires different and more subtle personal skills than the prescriptive approach. This has to be incorporated in training programs. In the 1990s, Lederach (1997, p. 108) already called for training in Strategic Capacity and Relationship Building. Based on that, at the University of Innsbruck we developed an academic training program that emphasizes, among other things, personal contact skills of future conflict workers. We derived some postulates from the general principles of humanistic psychology and anchored them in our curriculum. The ABC of elicitive peace workers' pre-requisite consists in our approach therefore of:

A-wareness of their own physical, emotional, mental and spiritual limits;

B-alance between compassion and self-protection; and

C-ongruent communication.

From that follows that we place the personality of the conflict worker in the focus of attention in our academic training. We consider the peace worker at work as a balancing factor, yet nothing more than another element, a 'third party' (Ury, 2000, pp. 3-29) in the conflict, which is understood here relationally as a dysfunctional social system. This means that a peace worker can never be neutral or non-partisan, but in the best of all cases all-partisan. This requires high awareness of the Self, of the surrounding reality in the field and of the concepts of one's own mind in order to not get lost in fantasies, pre-concepts and values, but be able to resonate to the parties' statements, behaviors, feelings, needs and requests.

The roots of elicitive conflict transformation in humanistic psychology can easily be identified in these postulates. Let me recall the characteristics of self-actualizers that Abraham Maslow (1970, pp. 153-172), one of the founding figures of humanistic psychology, presented already in the late 1960s. I do not want to go into the methodological 
dispute about his work, because in Innsbruck we are not interested in a definition of who was historically, or is currently, self-actualized, but we use Maslow's list as a sort of a beacon or goal, well aware that hardly anybody reaches it. We accept that, although we are all theoretically capable of self-actualizing, most of us will not do so, or only to a limited degree. Also, Maslow (1970, p. 176) stated that there are no perfect human beings. He did not equate selfactualization with perfection. Self-actualization merely involves achieving one's potential. Therefore we do not claim that we produce, on a large scale, people who are perceived overmen or overwomen, such as Gandhi, Albert Schweitzer, Martin Luther King, Nelson Mandela or Mother Theresa, but we provide a framework that allows our students to test their potential and envisage the beacon of their self-actualization. People always achieve self-actualization in their own unique way, but they tend to share certain characteristics. Maslow identified 15 characteristics of self-actualizers. I add several with an intercultural aspect and list them here, slightly modified, as 20 central virtues of elicitive peace workers, according to our experience of the past decade.

Elicitive conflict workers:

1. perceive reality efficiently and tolerate uncertainty and stress;

2. accept themselves, others and human nature for what they are;

3. are spontaneous, natural and genuine in thought and action;

4. are problem-centered and need little praise or popularity;

5. are able to concentrate intensely and have a sense of constructive humor;

6. are benevolent, empathic, patient and concerned for the wellbeing of others;

7. do things creatively even if they do not possess great talent for them;

8. are able to comply or break with conventions but they are not purposely unconventional;

9. are independent, self-sufficient and autonomous;

10. appreciate simple and commonplace experiences;

11. establish satisfying interpersonal relationships, friendship and love with a few people;

12. have a certain need for privacy and solitude;

13. are democratic and unprejudiced;

14. hold strong ethical standards, though not necessarily in a conventional sense;

15. are capable of detachment from their own culture;

16. can conform to or break with cultural conventions;

17. are able to compare cultures without judgment or blame;

18. refine their energies and qualities constantly;

19. treat conflicts as constructs of the mind and not as objective facts that could be fixed with appropriate remedies; they know that conflicts can (only) be deconstructed in the mind of the parties (human beings); 20. know peak experiences: feelings of ecstasy, wonder and awe, the loss of position in time and space.

While most of these things have been both scientifically tested and common wisdom, the final point might cause surprise here, because it seems to point rather to an individual religious or spiritual direction than to applied peace work for communities or societies. However, it is a necessary consequence of the system of transrational layers that I discussed before. Because spiritual-policitary consciousness stems from the experience that human beings enter this world of space and time like leaves on a tree (Naranjo, 2005, p. 138). This makes the difference in feeling, thinking, speaking and acting to moral, modern or postmodern approaches. It calms the archaic fears for life or survival and unites people with existence. Therefore the search for peace-experience in elicitive conflict transformation equals the spiritual search for peak-experience in mysticism.

Elicitive conflict transformation, thus, has a lot to do with courage: daring new tasks and methods and risking failure; not being afraid to express one's thoughts and feelings and risking being unpopular because of them; combining narrative elements in an unconventional or unexpected way and winding it up with humor; and accepting intuition as a legitimate aspect of one's personality, which does not necessarily have the same communication pattern as reason. Elicitive conflict workers share a drive to find order in chaotic situations, the interest in finding unusual problems as well as means and ways of transformation, the ability to make new connections and challenge traditional assumptions, the ability to balance idea creation with testing and judgment, the desire to push the boundaries of their competence. And they are motivated rather by the task itself than by external rewards such as money, grades or recognition.

This is both the subject and method of our training in elicitive conflict transformation, and we try to give our students the confidence that they can apply the same once they become practitioners in the field of conflict work. But even if playfulness and intuition are a good start for conflict work, it is also good to be equipped with a toolkit of tested methods, and to be structured from the beginning in order to be flexible when the unavoidable surprises of conflict work appear.

\section{METHODS, TOOLS AND PRINCIPLES}

The toolkit of applicable methods in elicitive conflict transformation comprises practically all known techniques of 
breath-oriented, voice-oriented and movement-oriented techniques that have been developed in the frame of humanistic psychology, yoga, martial arts, dance, dynamic meditation, psychodrama, expressive theatre and more. Norbert Koppensteiner presents some of them more extensively in this issue. More can be found in Dietrich, 2011 (in German) and 2013 (English translation of the same). Therefore I list here, without further explanation, only some examples like Holotropic Breathwork, the Clarity Process, Vipassana, Intuitive Monologue and Dialogue, Paralinguistics, Mantra, Active Listening, Nonviolent Communication, Theme Centered Interaction, Five Rhythm Dance, Butō, Capoeira, Aikido, Theatre of the Oppressed, Theatre for Living.

We provide basic training in these methods for our students in Innsbruck, but each of these techniques requires a lot of time and practice before one becomes a master. And nobody can be a master of them all. However, knowing them and being experienced in some of them is crucial in elicitive conflict work. Whether a specific technique can be applied in conflict work has to be evaluated in situ. This is the responsibility of the conflict worker. From experience he or she will decide whether a specific technique is the proper tool. But we have seen that knowledge of these techniques increases the creativity of the peace worker enormously. It makes them scouts, scientists, and artists of conflict work. That is, by knowing many of these techniques and having some experience with them, the conflict workers tend to explore and experiment with new contextual methods derived from the situation and the relation with the conflicting parties. That is exactly what the elicitive principle of resonance indicates. This ability and courage characterize qualified conflict workers. And it enables them to provide the proper framework for the conflicting parties to explore new options and alternatives for their interaction - transformation. Because we can only talk about successful conflict transformation when parties elaborate, for themselves, and perceive in the end at least three (new) options for interaction, which they feel free to choose or reject without fear of punishment or hope for reward (Satir et.al., 1991, p. 167).

Since we advocate the TCI principle (Cohn, 2004, p. 206) that one has to be structured in order to be flexible in conflict transformation, we developed a specific method that we called elicitive conflict mapping. This is the main subject of Volume 3 of my Many Peaces trilogy about transrational peaces and elicitive conflict transformation. Josefina Echavarría Álvarez presents the tool briefly in this issue. Elicitive conflict mapping is not the same as conventional conflict mapping. It is a tool for finding and keeping orientation in applied conflict work. It helps the conflict worker in the analysis of dysfunctional relations, to find balance in the confusing web of themes, levels and layers of the conflict pyramid. Methodologically it is rather derived from mind mapping than from traditional conflict or crisis map- ping. Our method has its fundament in the three principles of correspondence, resonance and homeostasis.

Correspondence is a tantric principle that basically says that everything that happens between individuals has its equivalent in persons. Thus, the narrative about an interpersonal conflict tells the elicitive peace worker a lot about the internal processes, energies and blockades of the parties. It has to be considered that every change of external affairs and relations has an impact on the internal condition of the people involved - and vice versa. The energy of any conflict as a strictly relational issue finds its way always along these lines. Conflict work, therefore, can be started in and with personal as well as relational layers. The conflict worker just has to bear the principle of correspondence in mind and apply it when providing the framework for the transformative work and when eventually giving impulses.

Resonance is also a tantric principle that first of all applies to the relations of the conflicting parties. That is, in a conflict we will see and hear an expressed narrative about the controversies on the surface, but the parties simultaneously resonate with each other on all the layers that I have addressed in the first chapter of this essay. Since these layers are interconnected and influence each other, we will find that the driving force of a conflict is rarely the topic of the episode on the surface but rather a blockade or irritation on one of the deeper layers. Life energy stems from the epicenter and radiates through all layers of existence until it becomes visible in the surface of the episode. This radiation is influenced by all aspects of human encounters and relations. If it is blocked or irritated we perceive that as a conflict. Therefore elicitive conflict transformation tries to find the conflictive aspects as close to the epicenter as possible. Since the conflict worker is also a human being, he or she will resonate in the same way with the parties. Therefore self-awareness, awareness of the surrounding and of their own concepts in the here and now are so important. And that is why subtle contact skills are so crucial for conflict workers. They inevitably become a new element in the dysfunctional social system and alter it with their mere presence. Thus conflict workers have to be conscious about the effect of their presence, how they relate with the parties and change their environment and their relations. A well-trained elicitive conflict worker will contribute to balancing the system, whereas unaware actors may harm and destroy even more.

Homeostasis, finally, is a technical term that we took from General System Theory (Bertallanfy, 1968, p. 195). It describes the property of a system that regulates its internal environment and tends to maintain a dynamic stability. Conflicts are the result of disturbance of homeostasis in social systems. Elicitive conflict transformation hence contributes to a gradual change of the homeostatic imbalance in a social system through rapprochement to equilibrium on all layers, levels and between all themes, well aware that, due to the dynamic 
character of social systems, equilibrium is not a reachable end status but only a beacon for finding orientation in action.

These three principles, based on transrational philosophy, are virtually the main tools for elicitive conflict mapping. They help the conflict worker to draw a map of the conflict, understand its 'landscape. They serve in some way as a compass, sonar and map for the conflict worker. They help to draw a picture of the conflict. This is useful, because it gives orientation. Still, it has to be stressed that the tourist map is not the landscape; the conflict map is not the conflict. The map is a helpful tool. It still takes all the art and science of the conflict worker to move and act in the real social conflict. Therefore we consider the training of all the above mentioned virtues as essential before a conflict worker gets involved in other people's affairs.

\section{CONCLUSION}

Elicitive conflict transformation is a working principle that is rooted in the insights of transrational peace philosophy and provides elicitive conflict mapping as a tool for applied conflict work. The principles of 1) correspondence of intrapersonal and interpersonal layers, 2) homeostasis between general conflict themes and 3) resonance among the parties as well as between the conflict worker and each participant of a conflict on all layers, are the fundamental ingredients for this type of conflict work. It applies to all levels of society - grassroots, the middle range and top leaders - because all of them are human actors embraced by the global system. As a consequence, this method acknowledges the importance of basic material needs for human life and therefore for human relations, but it presumes that conflicts are rarely triggered only by an imbalance of resource supply or by a clash of mere material interests, be it in the individual, communal, societal or global context. It believes much more that conflicts are created in the minds of human beings. Therefore all aspects of human nature, not only the material ones, have to be considered in applied conflict work, since conflicts can only be transformed in the minds of human beings, as UNESCO put so well in the preamble of its 1945 constitution.

\section{References}

BERTALANFFY, Ludwig von (1976). General system theory: foundations, development, applications. New York: Georg Braziler. [First published 1968].

BHARATI, Swami Veda (1986). Yoga sūtras of Patañjali with the exposition of Vyāsa. Vol 1. Samādhi-pāda. Honesdale: The Himalaya Institute.

COHN, Ruth (2004). Von der psychoanalyse zur themenzentrierten interaktion.

Stuttgart: Klett-Cotta. [First published 1971].

DIETRICH, Wolfgang (2008). Variationen über die vielen frieden - Deutungen. Schriften des UNESCO Chairs for Peace Studies der Universität Innsbruck/1. Wiesbaden: VS Verlag. [English translation (2012). Interpretations of peace in history and culture (Many Peaces vol. 1). London: Palgrave Macmillan]. http://dx.doi.org/10.1057/9780230367715

DIETRICH, Wolfgang (2011). Variationen über die vielen frieden, $B d$. 2: elicitive konflikttransformation und die transrationale wende in der friedenspolitik. Schriften des UNESCO Chair for Peace Studies an der Universität Innsbruck/2. Wiesbaden: VS Verlag. [English Translation (2013). Elicitive conflict transformation and the transrational turn in peace politics (Many Peaces vol. 2). London: Palgrave Macmillan]. http://dx.doi.org/10.1057/9781137035066

GALTUNG, Johan (1990). “Cultural violence”. Journal of Peace Research. Vol. 27, no. 3, pp. 291-305. http://dx.doi.org/10.1177/0022343390027003005

LEDERACH, John Paul (1995). Preparing for peace: conflict transformation across cultures. Syracuse: Syracuse University Press.

LEDERACH, John Paul (1997). Building peace: sustainable reconciliation in divided societies. Washington: United States of Peace Press.

LEDERACH, John Paul (2003). The little book of conflict transformation. Intercourse, PA: Good Books.

MASLOW, Abraham (1970). Motivation and personality. New York: Harper \& Row.

NARANJO, Claudio (2005). The one quest. A map of the ways of transformation. Nevada City: Gateways Books. [First published 1972] 
O'CONNOR, Joseph; SEYMOUR, John (1992). Neurolingustisches programmieren. gelungene kommunikation und persönliche entfaltung. Freiburg: VAK Verlag. [First published in English (1990). Introducing neuro-linguistic programming. psychological skills for understanding and influencing people. London: Mandala].

QUITMANN, Helmut (1996). Humanistische psychologie. Göttingen, Bern, Toronto, Seattle: Hogrefe.

RUPPERT, Franz (2002). Verwirrte seelen. Grundzüge einer systemischen psychotraumatologie. Munich: Kösel.

SATIR, Virginia [et al.] (1991). The Satir model. Family therapy and beyond. Palo Alto: Science and Behaviour Books.
UNESCO (1945). The UNESCO Constitution. Adopted $16^{\text {th }}$ November 1945. [Retrieved 15 May 2013]. http:// portal.unesco.org/en/ev.php-URL_ $\mathrm{ID}=15244 \& \mathrm{URL} \_\mathrm{DO}=\mathrm{DO} \_\mathrm{TOPIC} \& \mathrm{URL}$ _SECTION=201.html

URY, William (2000). The third side. Why we fight and how we can stop. New York: Penguin.

WILBER, Ken (1995). Sex, ecology, spirituality: the spirit of evolution. Boston: Shambala Publications.

\title{
Recommended citation
}

DIETRICH, Wolfgang (2014). "A Brief Introduction to Transrational Peace Research and Elicitive Conflict Transformation" [online article]. Journal of Conflictology. Vol. 5, Iss. 2, pp. 48-57. Campus for Peace, UOC. [Consulted: $\mathrm{dd} / \mathrm{mm} / \mathrm{yy}]$.

http://www.uoc.edu/ojs/index.php/journal-of-conflictology/article/view/vol5iss2-dietrich/vol5iss2-dietrich-en

DOI: http://dx.doi.org/10.7238/joc.v5i2.1940

ISSN 2013-8857

The texts published in this journal are - unless indicated otherwise - covered by the Creative Commons Spain Attribution 3.0 licence. You may copy, distribute, transmit and adapt the work, provided you attribute it (authorship, journal name, publisher) in the manner specified by the author(s) or licensor(s). The full text of the licence can be consulted here: http://creativecommons.org/licenses/by/3.0/es/deed.en.

\section{About the author}

\author{
Wolfgang Dietrich \\ wolfgang.dietrich@uibk.ac.at
}

UNESCO Chairholder for Peace Studies. Director of the MA Program for Peace Studies. University of Innsbruck, Austria. 